\title{
Principals' Understanding of their Role in Establishing a Positive and Enabling School Culture in Chinese and South African Public Primary Schools - Report on the Pilot Study
}

\author{
Eric Eberlein
}

\author{
Department of Education Management and Policy Studies, University of Pretoria, South Africa \\ Wang Zhichao \\ Department of Educational Management, North-East Normal University, China \\ eric.eberlein@up.ac.za; wangzc340@nenu.edu.cn
}

\section{Doi:10.5901/mjss.2014.v5n27p1178}

\section{Abstract}

This paper reports the results of an investigation into principals' understanding of their role in establishing a positive and enabling school culture in Chinese and South African public primary school. The culture of a school, defined as the intangible foundation of norms, values, rules, beliefs and common assumptions that govern and determine not only the behaviour of all the role players in a school, but also the attitude of these role players towards the school and the character and success of the teaching and learning that takes place there, has a substantial impact on the performance of the school and its learners. The research question that guided this study was "How do school principals in primary schools in South Africa and China understand their role in the establishing and maintaining of an enabling school culture?" With the definition of school culture as conceptual framework, this qualitative case study gathered data through the use of semi-structured interviews, observations and questionnaires. Primary findings include the fact that principals in both China and South Africa misunderstand the concept of school culture and also underestimate their role in the establishing and maintenance of positive school culture. Finally, it is also clear from the interviews that schools with a positive culture share certain characteristics - a greater distribution of leadership responsibility, a culture of educator empowerment and development and a strong presence of pastoral care for both learners and educators.

Keywords: School culture,

\section{Introduction and Background to the Study}

Under the auspices of a Memorandum of Agreement between the University of Pretoria (UP), South Africa and NorthEast Normal University (NENU) in Changchun, China, two teams of researchers from these institutions initiated a project to investigate the state of the school principalship in the two countries. The following aspects of the principalship were identified as focus points for the project: (1) the state of the principalship in both urban and rural settings in the two countries, (2) the pathways to principalship, (3) the impact of the principal's leadership practice on learner achievement, (4) the role of the principal in the development of professional learning communities in schools, and (5) the principal's contribution to the development of a positive and enabling school culture. This paper reports on the findings of the pilot study into the last of these focus areas, that is, the principal's contribution to the development of a positive and enabling school culture.

Although the scope of the project called for the participation of at least fifteen schools, it was decided that each research team would initially pilot the study at only four schools. Ultimately though, although data from four Chinese schools was used, the data from only three South African schools was included in the pilot study. The omission of the fourth South African school was necessitated by problems experienced during the data collection and recording process at that school.

Determining the terms of reference for the study also proved challenging - the differences between the South African and Chinese educations systems made decisions on matters such as the size and location of schools to visit difficult. So for example, a large public primary school in South Africa would have an enrolment of between 1200 and 1400 learners, while a large school in China would have an enrolment of up to 10000 learners, while the distances to travel in China in order to visit what is considered 'rural' schools in that country made the participation of such schools impractical. As a result, the teams ultimately selected the types of schools at which they felt they would gain the easiest 
access and where they felt that they would be able to collect the richest data.

The team from the UP thus elected to visit four medium-sized so-called under-resourced primary schools in the Limpopo province of South Africa. Under-resourced school are schools that fall into financial quintile 1, 2 or 3 and are therefore completely reliant on the State for all aspects of their funding - these schools may not collect any additional school fees from parents to bolster their coffers. The NENU team elected to collect data at four smaller urban primary schools in the Chao Yang district of the city of Changchun, which is situated in China's Jilin province.

Data was collected by conducting individual interviews with the principals of the participating schools in both South Africa and China and by the use of a questionnaire on various aspects of the principalship. It must be noted here that this questionnaire, for reasons of ethics, was not administered to the learners in South African schools, and was therefore only completed by the educators, while both educators and learners completed the questionnaire in the Chinese schools. South African researchers also, in addition to the instruments mentioned above, recorded their observations at the four schools using an observation protocol design for the purpose.

In order to illuminate the concepts and the results of this section of the project, this paper will explore the concept of school culture - literally the what, who and how of school culture. It will then report the findings of the field work conducted into the principals' role in the development of a positive and enabling school culture. Finally the paper will conclude with a discussion of the themes that emerge from the data and what actions or changes, if any, they dictate with regard to this important aspect of the principalship in Chinese and South African schools.

\section{Brief Literature Review - School Culture}

Hess and Kelly (2005) liken modern school principals to "small business executives" or "battlefield commanders" who must lead their schools to new levels of effectiveness, and state that the skill and knowledge of these principals matters more now than ever before, while Bush (2007) believes that the quality and effectiveness of education leadership and management makes a significant contribution to both organisational and learner outcomes, results and performance. This contribution to the effectiveness and success of the school includes, by the very nature of the task of the principal, aspects such as the development and maintenance of a positive and enabling school culture.

So if culture is 'the way we do things here', what is school culture? Schools are social systems with their own unique and individual cultures. According to the actual situation and the history of the development of each school, different schools form their own unique school culture from the prevailing "...systems and standards, social structures, attribution statements, values and goals" (Banks \& Banks, 1995). Sergiovanni and Starratt (in van der Westhuizen, 2007) define school culture as "rules, norms, values, beliefs and discipline which determine the behaviour of those in the school", which ties in well with what Mentz in the same source (2007) believes, namely that school culture "consists of a set of common assumptions, meanings and values which form the background for all behaviour at the school". Swanepoel calls these values, norms, rules and assumptions the school's "intangible foundation" (van der Westhuizen, 2007) and adds that, in addition to this intangible foundation, a school's culture consists of what he calls "tangible manifestations"' - visible and notable elements of the school culture such as "rituals, traditions, symbols" etc. (van der Westhuizen, 2007). School culture can therefore be defined as the intangible foundation of norms, values, rules, beliefs and common assumptions that govern and determine not only the behaviour of all the role players in a school, but also the attitude of these role players towards the school and the character and success of the teaching and learning that takes place there. This intangible foundation is manifested in visible elements such as the school's rituals, symbols, traditions etc. The existence of this culture is the manifestation of the core values which reflect a school's beliefs, attitudes and behaviours (Philips, 1993). On the whole, school culture plays an important role in forming the identity of the role players (educators, learners, parents) involved in the school, and also contributes significantly to the extent to which these role players identify themselves with the school. Furthermore, the school's culture motivates their actions and their participation in the activities of the school, while it also enhances the school's vitality and promotes communication and cooperation not only among the school's role players but also between these role players and the school.

On the one hand, a school's culture provides a clear set of standards of behaviour and values to help role players in the school act in accordance with this standard. Guided by this framework of school culture, every educator and learner will regulate his or her own behaviour, thus leading to the formation of a kind of behaviour culture with characteristics specific to that school. This culture will be represented through the interaction between educators and school leaders, educators and learners, school leaders and learners, learners and learners and educators and educators.

On the other hand, a school's culture is "the consensus of school organization members" (Yin Chong Cheng, 1992), and represents the history and development of the school. As mentioned earlier, this kind of culture tends to stimulate role players' identity as well as their sense of belonging and pride, which is invaluable to the school in its efforts 
to achieve its organizational goals.

Although many and varying factors both influence and determine the success of a school, a factor that is often overlooked or underestimated by school leaders is school culture. Jansen and Xaba in Van der Westhuizen (2007 warn that school leaders should not make the mistake of underestimating the role their schools' culture plays in determining the success of these educational institutions. They go on to state that the prevalent culture in a school, whether it is positive or negative, affects and influences both the educators and the learners of that school in all aspects of the school's operation, including its instructional, academic, sporting and cultural activities and achievements. This is echoed by Kruger (in van Deventer, 2007) when he says that more and more role players are realising the influence that school culture has on the success of both the teaching and learning that takes place in a school and on the success of the school as a whole. This influence also extends, as mentioned earlier, to the educators', parents' and learners' attitude towards the school, both while they are at school and also as it is displayed where they live in- and interact with the community served by the school (van der Westhuizen, 2007). In this regard Jansen and Xaba agree with Sergiovanni and Starratt who believe that the culture of a school has a greater influence on what the educators and learners of that school believe and think that any prescription or communication from a central education authority or department (2007).

However, because, school culture is the consensus of organizational members, it tends, according to Duke et al (2010) to perpetuate itself, eventually becoming out-dated and consequently hindering the essential process of on-going development and improvement. Generally speaking then, a school's culture will naturally attempt to maintain the status quo, this being true for both good schools and weak schools alike (Duke et al, 2010). A school's culture can only promote the development and improvement of the school if the culture itself is flexible and receives special attention and nurturing (Duke et al, 2010), or as Sparks (2013) puts it, improving the climate of a school that is struggling to meet the academic and social demands of the community it serves can be the foundation for both an extended period of school improvement and a way to have an immediate and obvious positive impact in both that school and that community.

So what is the link between school culture and school effectiveness? Jansen and Xaba (van der Westhuizen, 2007) describe aspects such as "leadership, governance, academic achievement and an orderly learning environment" as indicators of school effectiveness, aspects which they also believe are part of the tangible manifestations of school culture as explained above. In other words, because these indicators of school effectiveness can be described as tangible manifestations of the intangible foundation of a positive school culture, that positive school culture has a definite influence on the effectiveness of a school. School culture is, according to Reeves (2007), one of the key factors in school improvement. He postulates that, if lacking the support and framework of a positive school culture, all efforts at school improvement and reform will lose a most powerful aide and might well face failure (2007). Finally, the 2011 study by Fryer (TNTP, 2012) of the 'no excuses' charter schools in New York revealed that as much as $50 \%$ of the variation in performance and effectiveness between schools can be attributed to the differences in the cultures of those schools.

\section{Conceptual Framework}

Because this study seeks to describe the principal's contribution to the development of a positive and enabling school culture, this study employed as its conceptual framework the composite definition of school culture proposed earlier, namely that school culture entails the intangible foundation of norms, values, rules, beliefs and common assumptions that govern and determine not only the behaviour of all the role players in a school, but also the attitude of these role players towards the school and the character and success of the teaching and learning that takes place there. As mentioned earlier, this intangible foundation is manifested in visible elements such as the school's rituals, symbols, traditions etc.

Xie and Ma (2005) describe the different dimensions of school culture in the "Iceberg Structure Table" of school culture, as reflected in Table 1. It is believed that use of this description of the different dimensions of school culture, combined with what Swanepoel calls the 'tangible manifestations' and 'intangible foundation' of school culture (van der Westhuizen, 2007) will assist in placing the principals' understanding of school culture in perspective. 
Table 1 - Iceberg Structure Table of School Culture

\begin{tabular}{|c|c|c|}
\hline Basic Components & Content & Characteristic \\
\hline $\begin{array}{l}\text { Dominant components } \\
\text { 'Tangible manifestations' } \\
\text { (van der Westhuizen, 2007) }\end{array}$ & $\begin{array}{l}\text { Way of doing things } \\
\text { - School hierarchy } \\
\text { - School buildings and arrangements } \\
\text { - Ceremony and Ritual } \\
\text { - Sole models and stories } \\
\text { - Classroom instruction behaviour }\end{array}$ & Can be observed and measured \\
\hline Grey areas & School tradition & $\begin{array}{l}\text { Semi-explicit } \\
\text { Semi-implicit }\end{array}$ \\
\hline $\begin{array}{l}\text { Hidden components } \\
\text { 'Intangible foundation' } \\
\text { (van der Westhuizen, 2007) }\end{array}$ & $\begin{array}{l}\text { - Beliefs } \\
\text { - Behaviour } \\
\text { - Intention }\end{array}$ & Long term co-habitation \\
\hline
\end{tabular}

The interview schedule as well as the educator/learner questionnaire and observation protocol used to collect data were therefore developed to include descriptions of the elements of school culture as described above, examples of these elements being the rules, beliefs and common assumptions of the principal, the educators and the learners regarding the school's culture, as well as the symbols, rituals and traditions that form the visible manifestation of that culture.

\section{Research Methodology}

This study was conducted from an interpretivist perspective, thus allowing the researcher to "establish how participants (principals, educators and learners) make meaning of a specific phenomenon" (developing a positive and enabling school culture) by analysing their "perceptions, attitudes, understanding, knowledge, values, feelings and experiences" (Nieuwenhuis, 2007) As far as methodology is concerned, this qualitative study (Creswell, 2008) used a case study design or "the study of an instance in action" (Alderman in Cohen, Manion \& Morrison, 2009) to study "a specific instance that is frequently designed to illustrate a more general principle" (Nisbet \& Watt in Cohen et al, 2009). The case in this instance is a variety of public primary schools in the Limpopo and Jilin provinces of South Africa and China respectively, while the phenomenon under investigation is the principal's role in the development of a positive and enabling school culture.

As alluded to in the introduction, this study drew its data from four medium-sized so-called under-resourced primary schools in the Limpopo province of South Africa and four smaller urban primary schools in the city of Changchun, which is situated in the Jilin province. The sample for this study was therefore selected purposively as well as for convenience (Cohen et al, 2009).

In order to insure the comprehensiveness of the data (Cohen et al, 2009), semi-structured interviews were conducted with the principals of the eight schools to gather data regarding the beliefs, common assumptions, perceptions and attitude of the principals regarding the school culture and specifically the culture in their school. Although the second data gathering instrument, a comprehensive questionnaire for completion by the educators (SA) and educators and learners (China) of the eight schools contained questions covering all five aspects of the principalship mentioned in the introduction to this paper, only the answers to the questions pertaining to school culture were extracted and analysed for the purposes of this paper. In addition to these two instruments, observation conducted at the South African schools used to better triangulate (Creswell, 2008) the data collected during interviews and with the educator survey and to provide additional data on the schools' cultures, as well as the symbols, rituals and traditions that form the visible manifestation of the South African schools' cultures.

Finally, all the data was coded, inductively analysed (Mouton, 2006) and related within the conceptual framework to the primary research question. This allowed the research findings to "...emerge from frequent, dominant or significant themes inherent in the raw data" (Nieuwenhuis, 2007).

\section{Findings}

\subsection{Introduction}

The findings of this pilot study will initially be discussed by country, after which differences and similarities will be 
highlighted and discussed.

In the conclusion to the paper, the researchers will set out the dominant themes that emerge from the overall data per school and from the study as a whole, after which will follow a brief section on preliminary conclusions and recommendations that can reasonably be made at the hand of these themes.

In order to ensure anonymity and confidentiality, each South African school will simply be identified in this report as either School SA-A, School SA-B or School SA-C, while the Chinese schools will be identified as C-A, C-B, C-C and C-D.

\subsection{Findings in Chinese schools}

\subsubsection{Culture development as a role of the principal}

Three significant findings emerge from the data collected in Chinese schools. The first of these is that, although the principals of the four schools understand, in broad terms, their roles and responsibilities as principals, none of them included any mention of establishing and maintaining a positive and enabling school culture as part of these responsibilities.

The principals of Schools C-B, C-C and C-D all identified their primary role as that of leader of instruction at the school, while the principal of School C-A felt that management is his primary function. It is significant to note that none of the four the principals mentioned their role in the construction of their schools' cultures, therefore seemingly ignoring school culture's role in the school development or transformation process.

In this school development or transformation process, the more traditional Chinese school culture is often an obstacle to development and transformation, while the reform of a school's culture often serves as a booster to development and transformation. The fact that none of the four principals identified the development and maintenance of a positive school culture as part of their primary functions tells us that there are some misunderstandings among principals about the function and importance of school culture in the school development and transformation process.

While instructional leadership in fact also emphasise the importance of school culture and instructional leaders are seen by Mortimore (1993) as culture builders who strive, through the creation of academic pressure, to facilitate the learners' achievement of the schools' expectations and academic standards, these initial findings suggest that many principals may still be acting predominantly as leaders of instruction rather than as transformational leaders (Bamburg \& Andrew, 1990).

\subsubsection{The nature of school culture and principals' understanding of the concept}

When asked to describe the culture of their schools, the four principals described their school's cultures as 'happy and quality education' (School C-A), 'traditional culture' (School C-B), 'developing education' (School C-C) and 'native aesthetic education' (School C-D). However, from their descriptions of the culture at their respective schools, it became clear that they all narrowed down their understanding of school culture to a one-dimensional concept, thus limiting the effect and potential impact of school culture on the development and transformation of their schools.

All four principals narrowed down their understanding of their schools' cultures to a description of their schools' characteristics and the activities they and their schools are involved in that relate to school culture - these relate very strongly to the 'dominant components' identified by Xie and Ma (see table 1 above). It also became clear that these four schools' cultures focus almost exclusively on the learners, which might be seen to weaken the role and function of school culture.

Undoubtedly, every school has its own culture, and that this is the manifestation of values formed under the leadership of the principal. However, school culture does not only include such explicit aspects as posters and slogans, the condition and decoration of the buildings, school rituals and traditions and the learners' behaviour - it also includes the deeply rooted values and beliefs that have been internalized and integrated with the personal values of the role players in the school. Therefore, if principals seek representation of school culture only from learners and neglect the input of - and the role played by educators in school culture construction, the resulting culture may lack some crucial elements and may therefore affect the function of principals' transformational leadership.

\subsubsection{Summary of findings and recommendations - China}

Although the Chinese principals who participated in this pilot project understand their roles as school principals, they appear to focus more on the instructional side of their leadership and management role and less on the developmental 
and transformational side of the position.

The Chinese principals also appear to have a solid understanding of the concept of school culture, but appear to narrow their development and maintenance of their schools' cultures down to the dominant and observable aspects such as posters, slogans, the condition and decoration of the buildings, school rituals and traditions and learners' behaviour, while neglecting the 'deeper' and more impactful aspects of school culture as described by Xie and Ma (2005).

Finally, the principals of the Chinese schools, in their efforts to establish and develop school culture, appear to focus almost exclusively on the input from and impact on the learners, to the exclusion of other role players (such as educators) who have important contributions to make in this regard.

It is recommended that, considering the needs of all the role players in the process of school culture development and maintenance, the principal should focus on such development as a shared function so that it becomes the cornerstone of school change and transformation. In this regard, principals should emphasize the role of educators in school culture development and maintenance. Being subjects of instructional activities in the school and also the main participants in school change, educators have a decisive influence on the success or failure of school change.

It is further recommended that principals share some of the power of their office in the development and maintenance of school culture. Power sharing is a part of school culture reconstruction. Power sharing means that principals should clearly define the functions of different groups involved in the process of culture development and maintenance. For example, the innovators among the educators may be recruited onto the leadership team. Enhanced self-power will assist educators to treat themselves as leaders and participants in the process of development rather than just passive followers, will help them to pay attention to their own values, will help to eliminate a sense of insecurity that comes with change and development and will also promote and contribute significantly to educator development.

\subsection{Finding in South African schools}

\subsubsection{School SA-A}

The principal of School SA-A sees his key functions as planning and proper resource management. He understands what school culture is ('...how we do things here...'), and acknowledges that the current culture does not accurately reflect the school's vision and mission. He identified the major problems as late-coming and absenteeism of both learners and educators. He believes all role players involved in the school - educators, parents, learners and the School Management Team, are responsible for the development and continuation of a positive and enabling culture, and identifies the improvement of teamwork, proper curriculum planning and a revision of the school's vision and mission as his possible contribution to the improvement of his school's culture.

From observation done at the school it is clear that the relationships between the educators and learners, among educators themselves and between the educators and the principal are formal and respectful. The school's administration area, classrooms and school grounds are generally neat and tidy, with the exception of the learner bathrooms, which were found to be very dirty and unhygienic. General discipline among educators and learners alike was observed to be good, and the school appears to make every effort to protect teaching and learning time.

The questionnaire completed by educators revealed that they believe that the school has a strong culture of teaching and learning, and that they feel respected by the principals and by learners. Matters that might be improved upon include recognition by the principal of hard work among both educators and learners, and the development of a culture of celebrating learner successes. Comments made by educators in the open-ended section of the survey were overwhelmingly positive and supportive of the principal.

\subsubsection{School SA-B}

The principal of School SA-B described his key functions as managing the curriculum and fostering good relationships between the school and the community. He also highlighted his responsibility to cooperate with the School Management Team and to develop and assist educators. He described the culture of his school as "dwindling", a situation he ascribes to the recent growth in both learner and educator numbers experienced by his school and the Provincial Education Department's policy of 'matching', i.e. to appoint educators to posts in his school without advertising them, thus denying the school any input in these appointments. Apart from this, he also mentioned late-coming and absenteeism among both educators and learners, a lack of commitment to teaching and learning from educators and a lack of team work and cooperation, especially with, from and within the School Management Team. When asked to offer suggestions on what he could do to overcome these barriers, he passed the responsibility for this on to others, mentioning what in his opinion 
the circuit manager, the School Management Team and the Provincial Education Department should be doing in order to improve the culture of his school.

From the researcher's observation it is clear that, although the relationships between learners and educators are sound and respectful, relationships among the educators and between the educators and the principal are strained. As far as the school's physical facilities are concerned, although relatively well equipped in terms of furniture etc., there are signs a lack of regular cleaning and maintenance, with most classrooms and offices appearing dusty and unkempt. Teaching and learning appeared to be taking place in the Foundation Phase (Grades 1 to 3), but the same could not be said of the Intersen (Grades 4 to 6) and the Senior Phase (Grade 7), where classrooms full of learners were often left unsupervised, and then became noisy and unruly. It is also clear from observation and from the arrangements made to allow educators to complete the survey that the protection of teaching and learning time is not a school priority.

Finally, when one considers that only $52 \%$ of the educators indicated that they believe the school has a strong culture of teaching and learning, together with the fact that the majority of scores as well as the comments provided by educators indicate a wide-spread dissatisfaction with the principal's management style and practice, then the scope and the depth of the challenges to the school's culture become evident. It is very interesting to note here how, in discussing ways in which to improve the school's culture, the principal disregards the key responsibilities that he identified at the beginning of the interview (to assist educators in doing their job, to develop educators and to cooperate closely with the school's SMT), and places the responsibility for the improvement of his 'dwindling' culture elsewhere, namely on external stakeholders such as the circuit managers and the Provincial Education Department and on what he calls 'them', the School Management Team.

\subsubsection{School SA-C}

The principal of School SA-C described his key responsibilities as the management of the various management areas in the school. He reported that the school's vision and mission are the result of a widely participative campaign that had included parents, educators and learners. He is concerned about the impact his school's status as a quintile 3 school (the school is not permitted to collect additional school fees from parents) might have on the quality of education it is able to offer. The school hosts regular parent and community meetings and appears to enjoy strong support from these stakeholders as well as from others such as the local clinic and the South African Police Service. The greatest challenges to the improvement of the school's culture he identified as the lack of financial support from parents and the wide-spread late-coming among learners. He felt his own most important contribution the school's culture would be to foster a stronger sense of pastoral care among his educators.

From observation of the school it is clear that it enjoys good relationships with the parent community, and also that the relationships between learners and educators and among educators are on solid ground. Punctuality and learner discipline reflect the educators' and principal's desire to protect teaching and learning time. As far as the facilities are concerned, while some classrooms were found to be neat and tidy, many were not as well looked after. The condition of the learners' toilet facilities is especially worrisome. Finally, despite these facilities-related challenges, the overwhelmingly positive response by educators to virtually every section of the educator survey speaks of a school with an essentially sound and positive school culture.

\subsubsection{Summary of findings and recommendations - South Africa}

Of the three schools discussed here, two enjoy an essentially sound and enabling school culture, while one school, School SA-B, does not. Key factors that emerge from the data on the two schools with a positive school culture are the following:

- Both principals understand the importance of the vision and mission of the school and the need for advocacy and 'buy-in' from all stakeholder

- Both principals believe in the importance of sound relationships at all levels of and with all stakeholders involved in the school

- Both principals understand the value of cooperation and team work at all levels of the school

- Both principals encourage, support, cooperate with and care about and for their educators and are prepared to distribute leadership and management responsibilities as well as decision-making responsibilities with them. Because of this, both principals enjoy the admiration, support and cooperation of the majority of staff members at their school 
- Both principals understand the importance of fostering a pastoral culture which calls on educators to develop strong positive relationships with learners

- Both principals feel strongly about and make an effort to protect teaching and learning time

- Both principals understand and accept responsibility for their contribution to the development of a positive and enabling school culture

- Both principals can describe realistic strategies to improve the already essentially positive and enabling culture in their schools and are prepared to take the lead in implementing these strategies

These key factors highlight the vital contribution of the principal to the school culture, or 'the way we do things here'. By leading with compassion, transparency and understanding, by building strong positive relationships with educators, learners, parents and other stakeholders such as for example local clinics and the South African Police Service, and by taking cognisance of and accepting responsibility for the continuous process of developing and improving the school's culture, principals can go a long way to fulfilling this vital aspect of their task as principal.

\section{Discussion of Differences and Similarities - South Africa and China}

\subsection{Similarities between South African and Chinese principals}

\subsubsection{Principals' understanding of the concept of school culture}

Although all eight principals were able to identify and discuss elements of their respective schools' cultures, their understanding of the concept appears to be a very shallow one, focused mainly on the 'dominant components' such as the schools' hierarchies and the schools' systems and policies (South African schools) and the role models, stories, ceremonies and rituals (Chinese schools) as proposed by Xie and Ma (2005:8), at the apparent expense of the more deeply rooted and, in terms of development and transformation, important aspects such as beliefs, behaviour and intention.

\subsubsection{Principals' understanding of their role in- and responsibility for the development and maintenance of a positive and enabling school culture}

Principals in both China and South Africa describe their primary functions and responsibilities as management of the curriculum and instruction at school, and show a limited understanding of the role and importance of school culture or their role in- and responsibility for the development and maintenance of a positive and enabling school culture.

\subsection{Differences between South African and Chinese principals}

\subsubsection{Role players in the development of school culture}

While the South African principals at the two schools with a positive school culture identify a large number of role players (parents, learners, School Governing Body, School Management Team, the larger community) as being responsible for the development of a positive and enabling school culture, their Chinese counterparts appear to favour the learners as the primary source of and target for the development of such a culture.

\section{Conclusion}

This pilot study into Chinese and South African school principals' understanding of their role in establishing a positive and enabling school culture has highlighted some interesting similarities and differences between the principals in these two countries. The expansion of the study to fifteen schools in each country, together with a review of the findings of some of the other themes identified for attention as part of the overall NENU / UP research collaboration on the state of the principalship, particularly those investigating the impact of the principal's leadership practice on learner achievement, and the role of the principal in the development of professional learning communities in schools, is likely to shed new light on the nature of school culture and its importance in both learner achievement and school development, improvement and transformation. 


\section{References}

Bamburg, J. \& Andrew, R.. (1990). School Goal, Principals and Achievement. School Effectiveness and School Improvement, $3,175-$ 191.

Banks, C.A.M. \& Banks, J.A. (1995). Theory into Practice. Culturally Relevant Teaching, (3), 152-158.

Bush, T. (2007). Educational leadership and management: theory, policy and practice. South African Journal of Education, 27, 391-406.

Cohen, I, Manion, L. \& Morrison, K. (2009) Research Methods in Education, 6 th Edition. London: Routledge Falmer.

Creswell, J.W. (2008). Educational Research - 3rd Edition. New York: Pearson.

Department of Education. (2000). Norms and Standards for Educators. Retrieved September 18, 2013, from http://academicsun.ac.zal mathed/174/NORMS\%20AND\%20STANDARDS\%20FOR\%20EDUCATORS.pdf

Duke, D.L., Tucker, P.D., Salmonowicz, M., Levy, M. \& Saunders, S. (2010). Teachers' guide to school turnarounds. Rowman and Littlefield Publishers, Lanham, MD.

Eberlein, E. (2013). Managing the National School Nutrition Programme in under-resourced primary schools in Limpopo - practice, successes and challenges. Suid Afrikaanse Tydskrif vir Natuurwetenskap en Tegnologie, 32(1), 778-787.

Phillips, G. (1993). The School-Classroom Culture Audit. Vancouver, British Columbia: Eduserv British Columbia School Trustees Publishing.

Harris, A. (2004). Distributed Leadership and School Improvement: Leading or Misleading? Educational Management Administration \& Leadership, 32, 11-23.

Hess, F.M. \& Kelly, A.P. (2005). Learning to Lead? What gets taught in principal preparation programs. Retrieved on October 25, 2011, from http:/www.ksg.harvard.edu/pepg/PDF/Papers/Hess_Kelly_Learning_to_Lead_PEPG05.02.pdf.

Mortimore, P. (1993). School Effectiveness and the Management of Effective Learning and Teaching. School Effectiveness and School Improvement, 4, 290-310.

Mouton, J. (2006). How to succeed in your Master's and Doctoral studies - A South African guide and resource book - 10th edition. Cape Town: Van Schaik.

Nieuwenhuis, J. (2010). Qualitative research designs and data gathering techniques In: Maree, K (ed.), First Steps in Research. Pretoria: Van Schaik.

Reeves, D. (2007). How Do You Change Your School Culture? Educational Leadership, (1), 94-96.

Sparks, S.D. (2013). School Climate: Missing Link in Principal Training? Education Week. 32 (23), 8-12

Spillane, J.P. (2005). Distributed Leadership. The Educational Forum, 69, 43-150.

TNTP. (2012). Greenhouse Schools: How can we build cultures where teachers and students thrive? Downloaded from www.tntp.org

Van der Westhuizen, P.C. (ed). (2007). Schools as Organisations. Van Schaik. Pretoria

Van Deventer, I. (ed). (2007). An educator's guide to school management skills. Van Schaik. Pretoria

Van Deventer, I. \& Kruger, A.G. (eds). (2011). An educator's guide to school management skills (10th edition). Pretoria: van Schaik.

Cheng, Y (1992). A Preliminary Study of School Management Initiative: Response to Induction of Management Reforms. Educational Research Journal, (7) 21-32.

Xie, Y \&, Ma Y. (2005). Reconstruction School Culture: The main task of the Quality School. East China Normal University (Educational Science Edition. 1, 7-15. 